\title{
Revegetation with artificial plants improves topsoil hydrological properties but intensifies deep-soil drying in northern Loess Plateau, China
}

\author{
ZHANG Qingyin $^{1}$, JIA Xiaoxu ${ }^{2,3^{*}}$, ZHAO Chunlei $^{1}$, SHAO Ming' ${ }^{1}{ }^{1,2,3}$ \\ ${ }^{1}$ State Key Laboratory of Soil Erosion and Dryland Farming on the Loess Plateau, Northwest A\&F University, Yangling \\ 712100, China; \\ ${ }^{2}$ Key Laboratory of Ecosystem Network Observation and Modeling, Institute of Geographic Sciences and Natural Resources \\ Research, Chinese Academy of Sciences, Beijing 100101, China; \\ ${ }^{3}$ College of Resources and Environment, University of Chinese Academy of Sciences, Beijing 100190, China
}

\begin{abstract}
Knowledge about the effects of vegetation types on soil properties and on water dynamics in the soil profile is critical for revegetation strategies in water-scarce regions, especially the choice of vegetation type and human management measures. We focused on the analysis of the effects of vegetation type on soil hydrological properties and soil moisture variation in the $0-400 \mathrm{~cm}$ soil layer based on a long-term (2004-2016) experimental data in the northern Loess Plateau region, China. Soil bulk density (BD), saturated soil hydraulic conductivity (Ks), field capacity (FC) and soil organic carbon (SOC) in 2016, as well as the volumetric soil moisture content during 2004-2016, were measured in four vegetation types, i.e., shrubland (korshinsk peashrub), artificial grassland (alfalfa), fallow land and cropland (millet or potato). Compared with cropland, revegetation with peashrub and alfalfa significantly decreased BD and increased $\mathrm{Ks}, \mathrm{FC}$, and SOC in the $0-40 \mathrm{~cm}$ soil layer, and fallow land significantly increased FC and SOC in the $0-10 \mathrm{~cm}$ soil layer. Soil water storage (SWS) significantly declined in shrubland and grassland in the 40-400 cm soil layer, causing severe soil drought in the deep soil layers. The study suggested that converting cropland to grassland (alfalfa) and shrubland (peashrub) improved soil-hydrological properties, but worsened water conditions in the deep soil profile. However, natural restoration did not intensify deep-soil drying. The results imply that natural restoration could be better than revegetation with peashrub and alfalfa in terms of good soil hydrological processes in the semi-arid Loess Plateau region.
\end{abstract}

Keywords: soil drying; soil hydrological property; soil moisture; vegetation restoration; Loess Plateau

Citation: ZHANG Qingyin, JIA Xiaoxu, ZHAO Chunlei, SHAO Ming'an. 2018. Revegetation with artificial plants improves topsoil hydrological properties but intensifies deep-soil drying in northern Loess Plateau, China. Journal of Arid Land, 10(3): 335-346. https://doi.org/10.1007/s40333-018-0007-0

\section{Introduction}

Soil moisture is an integral component of the terrestrial ecosystem and it is related to different hydrological processes and ecological functions in different soil layers (Yang et al., 2012; Deng et al., 2016). The northern Loess Plateau region of China is facing an increasing water shortage (Wang et al., 2011; Liu et al., 2015; Deng et al., 2016, 2017) in the form of declining soil water. As a vital component of the hydrologic cycle, the dynamics of soil water can be altered by various

${ }^{*}$ Corresponding author: JIA Xiaoxu (E-mail: jiaxx@igsnrr.ac.cn) Received 2017-10-31; revised 2017-12-07; accepted 2018-03-16

C Xinjiang Institute of Ecology and Geography, Chinese Academy of Sciences, Science Press and Springer-Verlag GmbH Germany, part of Springer Nature 2018 
factors, including precipitation (Seneviratne et al., 2010), soil organic carbon (SOC) (Breuer et al., 2006), porosity, saturated hydraulic conductivity (Ks) (Wang et al., 2012) and especially vegetation type (Deng et al., 2016; Jia et al., 2017). Knowledge on soil-hydrological properties and soil water processes is critical for effective management of water resources and therefore successful restoration of vegetation in the semi-arid area (Jia et al., 2015; Deng et al., 2016; Wu et al., 2016; Zhang and Shangguan, 2016).

Vegetation restoration is encouraged globally due to its various ecological benefits (Malagnoux, 2007). In assessing the benefits of revegetation, its effect on soil-hydrological properties and on soil water storage (SWS) in different soil layers should be considered. Studies show that revegetation reduces soil bulk density (BD) (Breuer et al., 2006) and increases Ks (Zhang et al., 2013), infiltration rate (Wu et al., 2016) and SOC (Fu et al., 2010), and thereby improves soil hydrological properties. Soil moisture in surface layers is greatly influenced by rainfall or evapotranspiration and is a regular water source for vegetation growth (Fang et al., 2016). However, soil water in deeper layers has largely been ignored because it is both labor- and time-demanding for investigation. Fang et al. (2016) observed that shrubs can cause excessive depletion of deep soil water and ecological degradation in the semi-arid Loess Plateau region, China. Generally, soil water in the deep layers is not altered due to the insulation effect of upper soil layers (Wang et al., 2012). Soil water in the upper layers, however, is not sufficient to meet growth needs of cultivated perennial plants (e.g., peashrub and alfalfa) on the Loess Plateau (Yang et al., 2014). The roots of the cultivated plants penetrate into previously unexploited soil depths (Zeng et al., 2011; Fang et al., 2016). The balance between soil water supply and plant growth requirement is critical for not only the sustainability of the ecosystem, but also the productivity of semi-arid ecosystems (Issa et al., 2011).

The Loess Plateau, a severely eroded region in the world, is facing increasing water shortage and soil erosion (Shi and Shao, 2000). To mitigate soil erosion in the region, the Chinese government developed the Grain-for-Green Program, which croplands were reconverted into forests, shrubs and grass (Cao et al., 2009; Deng et al., 2014). Although the vegetation restoration has improved the soil physical properties and reduced soil erosion, high water demand of the introduced vegetation has resulted in soil desiccation and the formation of dry soil layers (Chen et al., 2008; Fu et al., 2012; Jia et al., 2015, 2017). With this, it is important to consider soil water use and sustainability of the vegetation restoration in the region.

The objective of this study was to determine the effects of 13 years of conversion from cropland to grassland (alfalfa and fallow for natural restoration) and shrubland (peashrub) on soil hydrological properties and SWS in the $0-400 \mathrm{~cm}$ soil profile in the semi-arid Loess Plateau region, China.

\section{Materials and methods}

\subsection{Study area}

The study was conducted at the Shenmu Erosion and Environment Research Station of the Institute of Soil and Water Conservation, Chinese Academy of Sciences. The station is located in Liudaogou watershed in Shenmu County, Shaanxi Province, China $\left(38^{\circ} 46^{\prime}-38^{\circ} 51^{\prime} \mathrm{N}\right.$, $\left.110^{\circ} 21^{\prime}-110^{\circ} 23^{\prime} \mathrm{E}\right)$. The study area is representative of the transitional belt that is subjected to both wind and water erosion. Based on 13-year meteorological data (2004-2016; Fig. 1), the mean annual precipitation is $417 \mathrm{~mm}$ and $73 \%$ of it occurs from June to September. The annual mean temperature is $7^{\circ} \mathrm{C}-9^{\circ} \mathrm{C}$. The soil is Calcaric Regosol (World Reference Base for Soil Resources), developed from low fertility loess. Throughout the region, perennial vegetation (e.g., alfalfa (Medicago sativa Linn.) and peashrub (Caragana korshinskii Kom.)) has been implemented in the past decade to mitigate soil degradation. The natural biomes of the region are bunge needlegrass (Stipa bungeana Trin.), with millet (Setaria italica L.) and potato (Solanum tuberosum L.) as the main grain crops. 

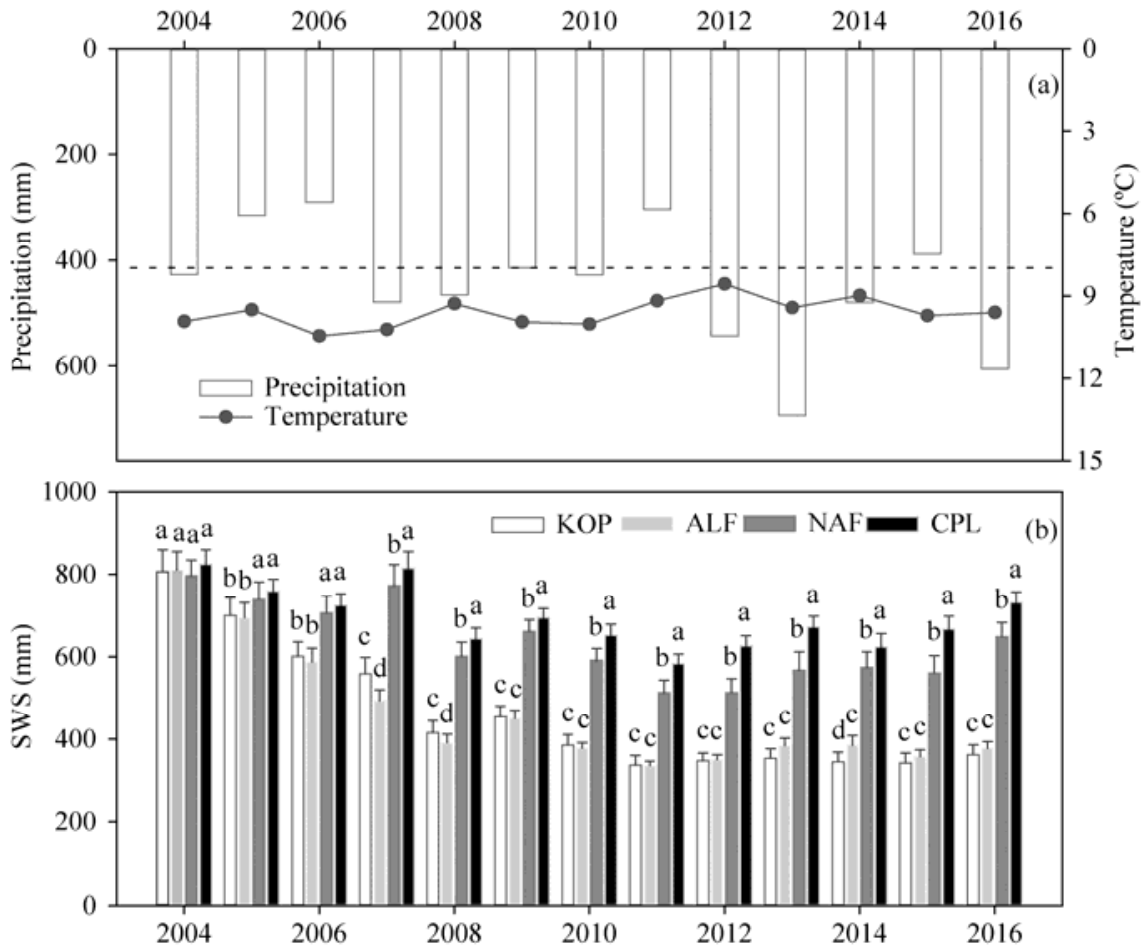

Fig. 1 Mean annual precipitation and annual mean temperature (a) and soil water storage (SWS) in the 0-400 $\mathrm{cm}$ soil layer (b) during 2004-2016. The black dotted line represents annual mean precipitation (417 $\mathrm{mm}$ ) during 1971-2016. Significant differences among land use types within the same time are denoted by different lowercase letters. The bars represent standard deviation for sample size of $n=11$. KOP, korshinsk peashrub (shrubland); ALF, alfalfa (grassland); NAF, natural restoration (fallow land); CPL, millet (cropland).

\subsection{Experimental design}

The experiment was set up on a large hillslope in 2003 following the experimental design documented in $\mathrm{Fu}$ et al. (2010). The hillslope was cultivated with millet (S. italica) for decades and abandoned for two years before the experiment. With the uniform landscape and the same land use before the start of the experiment, it was assumed that the plots had similar initial chemical and physical conditions. Each plot was divided into three equal parts: upper, middle, and lower hillslope positions. Thus there were, as a matter of fact, three replications of each vegetation treatment. The study had a total of four vegetation treatments: (1) shrubland (korshinsk peashrub), (2) artificial grassland (alfalfa), (3) fallow land (fallow for natural restoration) and (4) cropland (millet or potato). The size of each treatment plot was $61 \mathrm{~m} \times 5 \mathrm{~m}$ and the treatments were separated by $0.8 \mathrm{~m}$ buffer spaces. The row spacing of the shrubland was $70 \mathrm{~cm}$ and was not harvested or fertilized after planting. The row spacing of the grassland was $50 \mathrm{~cm}$, harvested (by cutting the straw near the soil surface) annually in late August (the period of peak biomass), and also was not fertilized. The fallow land was not cultivated or fertilized. Then the cropland was tilled to the depth of $20 \mathrm{~cm}$ in May and harvested in late August when the biomass was at its peak. The selected physical and chemical properties of the 0-20 cm soil layer in 2003 are given in Table 1 (Fu et al., 2010).

Table 1 Soil physical and chemical properties of the $0-20 \mathrm{~cm}$ soil layer in 2003

\begin{tabular}{lllllll}
\hline $\begin{array}{l}\text { Clay } \\
(\%)\end{array}$ & $\begin{array}{l}\text { Silt } \\
(\%)\end{array}$ & $\begin{array}{r}\text { Sand } \\
(\%)\end{array}$ & $\begin{array}{c}\mathrm{BD} \\
\left(\mathrm{g} / \mathrm{cm}^{3}\right)\end{array}$ & $\begin{array}{c}\mathrm{Ks} \\
(\mathrm{mm} / \mathrm{min})\end{array}$ & $\begin{array}{l}\text { FC } \\
(\mathrm{g} / \mathrm{g})\end{array}$ & $\begin{array}{l}\text { SOC } \\
(\mathrm{g} / \mathrm{kg})\end{array}$ \\
\hline 15.6 & 44.0 & 40.4 & 1.48 & 0.94 & 0.19 & 1.62 \\
\hline
\end{tabular}

Note: BD, bulk density; Ks, saturated hydraulic conductivity; FC, field capacity; SOC, soil organic carbon.

\subsection{Sampling and laboratory analyses}

From 26 July 2015 to 4 August 2016 (13 growing seasons after the start of the experiment), soil 
and plant biomass (aboveground and belowground) samples were collected every $5 \mathrm{~m}$ along the hillslope (a total of 11 sampling points per plot). Soil samples were taken along the hillslope for each plot at three depth increments $(0-10,10-20$ and 20-40 cm) using a 5-cm diameter tube auger. Soil samples passed through the $0.25-\mathrm{mm}$ mesh were used to determine SOC by the Walkey-Black method (Nelson and Sommers, 1982). We determined particle size distribution using the pipette method (Gee and Or, 2002) and classified it based on the USDA classification system. Undisturbed soil cores were collected using a soil bulk sampler with a 5-cm diameter and $5-\mathrm{cm}$ high stainless steel cutting ring (3 replicates) for each of the three soil depths. Ks was determined by the constant head method (Kanwar et al., 1989) and also oven-dried at $105^{\circ} \mathrm{C}$ before weighed for soil BD measurement. Soil capillary porosity was determined by placing the samples on moist filter paper, which allowed the soil to absorb water via capillary action (Wang et al., 2012). Field capacity (FC) was determined from the fitted soil-water characteristic curve using the centrifugation method (Wu et al., 2016).

Table 2 Particle size composition of soil in the $0-40 \mathrm{~cm}$ soil layer under the four land use treatments in 2016

\begin{tabular}{|c|c|c|c|c|c|c|}
\hline $\begin{array}{l}\text { Land } \\
\text { use }\end{array}$ & $\begin{array}{l}\text { Soil depth } \\
\quad(\mathrm{cm})\end{array}$ & $\begin{array}{l}\text { Clay } \\
(<2 \mu \mathrm{m}) \\
(\%)\end{array}$ & $\begin{array}{c}\text { Silt } \\
(2-50 \mu \mathrm{m}) \\
(\%)\end{array}$ & $\begin{array}{c}\text { Sand } \\
(>50 \mu \mathrm{m}) \\
(\%)\end{array}$ & $\begin{array}{l}\text { Porosity } \\
\quad(\%)\end{array}$ & Dominant species \\
\hline \multirow{3}{*}{ KOP } & $0-10$ & $7.91 \pm 1.53$ & $38.21 \pm 5.33$ & $53.88 \pm 6.79$ & $49.80 \pm 2.98$ & \multirow{3}{*}{ Caragana Korrshinkii Kom. } \\
\hline & $10-20$ & $8.16 \pm 1.60$ & $37.34 \pm 5.60$ & $54.49 \pm 7.12$ & $47.69 \pm 1.44$ & \\
\hline & $20-40$ & $8.81 \pm 1.72$ & $39.55 \pm 5.25$ & $51.64 \pm 6.88$ & $47.04 \pm 1.10$ & \\
\hline \multirow{3}{*}{ ALF } & $0-10$ & $8.87 \pm 1.19$ & $39.39 \pm 3.88$ & $51.73 \pm 4.68$ & $47.86 \pm 1.47$ & \multirow{3}{*}{ Madicago sativa Linn. } \\
\hline & $10-20$ & $9.66 \pm 1.57$ & $41.26 \pm 4.00$ & $49.08 \pm 5.36$ & $46.75 \pm 1.50$ & \\
\hline & $20-40$ & $9.69 \pm 1.98$ & $41.08 \pm 5.61$ & $49.22 \pm 7.36$ & $46.17 \pm 0.82$ & \\
\hline \multirow{3}{*}{ NAF } & $0-10$ & $8.52 \pm 1.18$ & $38.28 \pm 2.93$ & $53.20 \pm 3.92$ & $47.46 \pm 1.27$ & \multirow{3}{*}{$\begin{array}{l}\text { Stipa bungeana Trin.; Poa sphondylodes } \\
\text { Trin.; Heteropappus altaicus Willd. }\end{array}$} \\
\hline & $10-20$ & $9.08 \pm 1.71$ & $40.22 \pm 5.84$ & $50.70 \pm 7.42$ & $47.40 \pm 2.12$ & \\
\hline & $20-40$ & $9.91 \pm 1.01$ & $42.27 \pm 5.20$ & $47.82 \pm 6.00$ & $46.67 \pm 2.71$ & \\
\hline \multirow{3}{*}{ CPL } & $0-10$ & $8.08 \pm 1.25$ & $38.32 \pm 3.82$ & $53.60 \pm 4.73$ & $48.22 \pm 0.62$ & \multirow{3}{*}{ Setaria italic L.; Solanum tuberosum L. } \\
\hline & $10-20$ & $8.81 \pm 1.38$ & $39.90 \pm 6.26$ & $51.28 \pm 7.51$ & $47.53 \pm 1.44$ & \\
\hline & $20-40$ & $9.08 \pm 2.51$ & $39.45 \pm 6.05$ & $51.47 \pm 8.40$ & $46.34 \pm 2.43$ & \\
\hline
\end{tabular}

Note: KOP, korshinsk peashrub (shrubland); ALF, alfalfa (grassland); NAF, natural restoration (fallow land); CPL, millet (cropland). Mean \pm SD, $n=11$.

The aboveground biomass (AGB) measurements for shrubland, grassland, fallow land, and cropland were taken using $1.5 \mathrm{~m} \times 4 \mathrm{~m}, 1 \mathrm{~m} \times 1 \mathrm{~m}$ and $1 \mathrm{~m} \times 1 \mathrm{~m}$ subplots in late July 2016, respectively. Each biomass was then oven-dried at $70^{\circ} \mathrm{C}$ to a constant weight and weighed to determine AGB. The roots under the shrubland, grassland, fallow land, and cropland were extracted manually at $0-10,10-20$ and $20-40 \mathrm{~cm}$ soil depths in late July 2016 . Three sampling points were randomly selected in each plot using a $20 \mathrm{~cm} \times 20 \mathrm{~cm}$ quadrat and the collected roots were washed in flowing water. The fine roots $(<2 \mathrm{~mm}$ in diameter) were separated and oven-dried at $70^{\circ} \mathrm{C}$ to a constant weight and weighed to determine fine root biomass (FRB).

\subsection{In situ soil moisture measurement}

To monitor the temporal patterns of soil moisture for the shrubland, grassland, fallow land, and cropland in the northern Loess Plateau region, we established permanent plots for continuous profile soil moisture measurements along a hillslope in Liudaogou watershed. One plot $(61 \mathrm{~m} \times 5$ $\mathrm{m})$ was established in 2003 in the four vegetation treatments on a uniform slope $\left(12^{\circ}\right)$ facing the northwest. A total of 11 aluminum neutron-probe access tubes (each $420 \mathrm{~cm}$ in length) were installed at 5-m intervals along the midline of each plot. Volumetric soil water content (SWC) was measured in growing season once a month to the depth of $400 \mathrm{~cm}$ at $20-\mathrm{cm}$ intervals using the calibrated neutron probe (CNC 503DR Hydro probe, Beijing Super Power Company, Beijing, China) for the period 2004-2016 (Liu and Shao, 2016; Jia et al., 2017). There were a total of 78 (13 years $\times 6$ times) sampling events during 2004-2016, which data were used to analyze the 
temporal variations in SWC after revegetation. Then SWS was calculated from SWC and soil depth data.

\subsection{Statistical analysis}

Statistical analyses were conducted using the SPSS statistical package version 18.0 (SPSS 18.0, SPSS Inc., Chicago, IL, USA). One-way analysis of variance (ANOVA) and Least Significant Difference (LSD) tests were used to compare SWS in the 0-400 $\mathrm{cm}$ soil depth, aboveground and belowground biomass and soil properties (BD, Ks, FC, and SOC) within different vegetation treatments. The profile SWS data were analyzed for mean and standard deviations for the various soil depths under each vegetation type $(n=11)$. Post hoc multiple comparisons were evaluated at the 0.05 significance level.

\section{Results}

\subsection{Aboveground and belowground biomass}

The AGB of shrubland, grassland and fallow land was significantly higher than that of cropland $(P<0.05)$ (Fig. 2). Shrubland had the highest AGB $\left(626.4 \pm 179.3 \mathrm{~g} / \mathrm{m}^{2}\right)$, followed by fallow land $\left(216.3 \pm 21.7 \mathrm{~g} / \mathrm{m}^{2}\right)$, grassland $\left(197.3 \pm 28.8 \mathrm{~g} / \mathrm{m}^{2}\right)$ and then cropland $\left(54.7 \pm 9.5 \mathrm{~g} / \mathrm{m}^{2}\right)$.

Consistent with AGB, FRB for shrubland, grassland and fallow land was significantly higher than that for cropland at the $0-40 \mathrm{~cm}$ soil depth $(P<0.05$; Fig. 2). For the top $10 \mathrm{~cm}$ depth, fallow land had the highest FRB, followed by shrubland, grassland, and then cropland. For the $10-20 \mathrm{~cm}$ and 20-40 cm soil layers, shrubland had the highest FRB, followed by grassland, fallow land and cropland had the lowest.

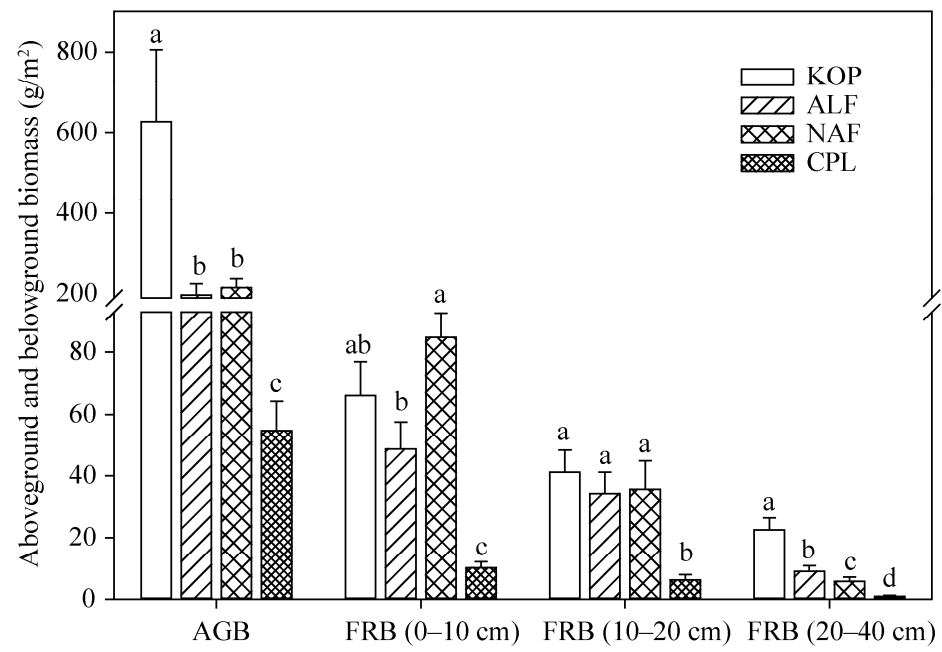

Fig. 2 Mean aboveground biomass (AGB) and fine root biomass (FRB) for the 0-10, 10-20 and 20-40 cm soil layers under the four land-use treatments in 2016. KOP, korshinsk peashrub (shrubland); ALF, alfalfa (grassland); NAF, natural restoration (fallow land); CPL, millet (cropland). Significant differences among land use types within the same soil layer are denoted by different lowercase letters. Bars represent standard deviations, $n=11$.

\subsection{Soil hydrological properties}

Soil BD under shrubland was significantly lower than those under grassland, fallow land, or cropland for the $0-10 \mathrm{~cm}$ soil layer. For the $10-20$ and $20-40 \mathrm{~cm}$ soil layers, there was no significance difference in soil BD under the four vegetation types $(P<0.05$; Fig. 3a).

Soil Ks under shrubland, grassland, and fallow land was significantly higher than that under cropland for the $0-10 \mathrm{~cm}$ soil layer, with the maximum value $(8.0 \pm 2.3 \mathrm{~mm} / \mathrm{min})$ observed under shrubland. Furthermore, the trends were similar and Ks increased with increasing soil depth (Fig. 3b).

Compared with cropland, soil FC increased by $27 \%$ under shrubland, $14 \%$ under grassland, and 
$11 \%$ under fallow land for the $0-10 \mathrm{~cm}$ soil layer. For the $10-40 \mathrm{~cm}$ soil layer, the trend in FC was similar for the duration of the restoration time (Fig. $3 \mathrm{c}$ ).

SOC under shrubland, grassland, and fallow land was significantly greater than that under cropland for the $0-10 \mathrm{~cm}$ soil layer. For the $10-40 \mathrm{~cm}$, SOC under shrubland significantly increased over that under cropland, but not for that under grassland and fallow land (Fig. 3d).
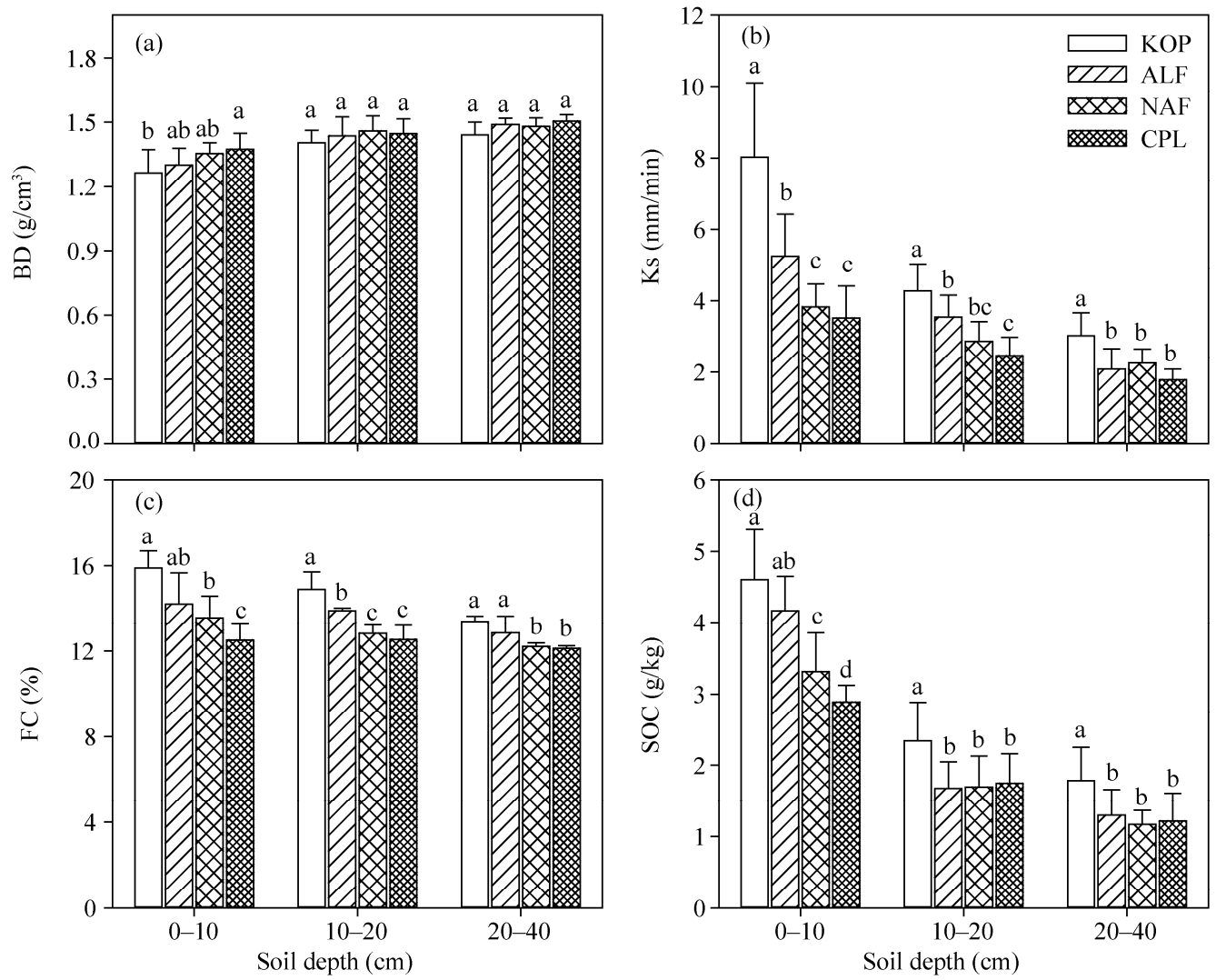

Fig. 3 Soil hydrological properties in different soil layers under the four land use treatments. Significant differences among land use types within the same soil layer are denoted by different lowercase letters. Bars represent standard deviations, $n=11$. KOP, korshinsk peashrub (shrubland); ALF, alfalfa (grassland); NAF, natural fallow (fallow land); CPL, millet (cropland). BD, bulk density; Ks, saturated hydraulic conductivity; FC, field capacity; SOC, soil organic carbon.

\subsection{Long-term variations in soil water storage}

Variations in SWS in the $0-400 \mathrm{~cm}$ soil layer under the four vegetation types are shown in Figures $1 \mathrm{~b}$ and 4 . In the $0-400 \mathrm{~cm}$ soil layer, SWS under shrubland and grassland significantly declined in the study area. SWS under fallow land was significantly lower $(P<0.05)$ than that under cropland, but significantly higher $(P<0.01)$ than those under shrubland and grassland. Overall, SWS was highest under cropland, moderate under fallow land and lowest under shrubland and grassland.

Throughout the period, SWS significantly decreased under shrubland, grassland, and fallow land (Fig. 5). There was significant $(P<0.01)$ decline in SWS $(2.2,5.6,6.6$ and $6.5 \mathrm{~mm} / \mathrm{a}$ respectively for the 40-100, 100-200, 200-300 and 300-400 cm soil layers) under shrubland. Consistent with the changes in shrubland, the 1.8, 4.8, 6.7, and $6.8 \mathrm{~mm} / \mathrm{a}$ decline in SWS was significant $(P<0.01)$ respectively for the 40-100, 100-200, 200-300 and 300-400 cm soil layers under grassland during the period 2004-2016. The rate of SWS decline under fallow land was much lower than those under shrubland and grassland. There was no significant difference in SWS among the four vegetation types for the $0-40 \mathrm{~cm}$ soil layers after 13 years of revegetation. This suggested that precipitation recharge was an important factor for soil moisture storage in the $0-40 \mathrm{~cm}$ soil layer. 

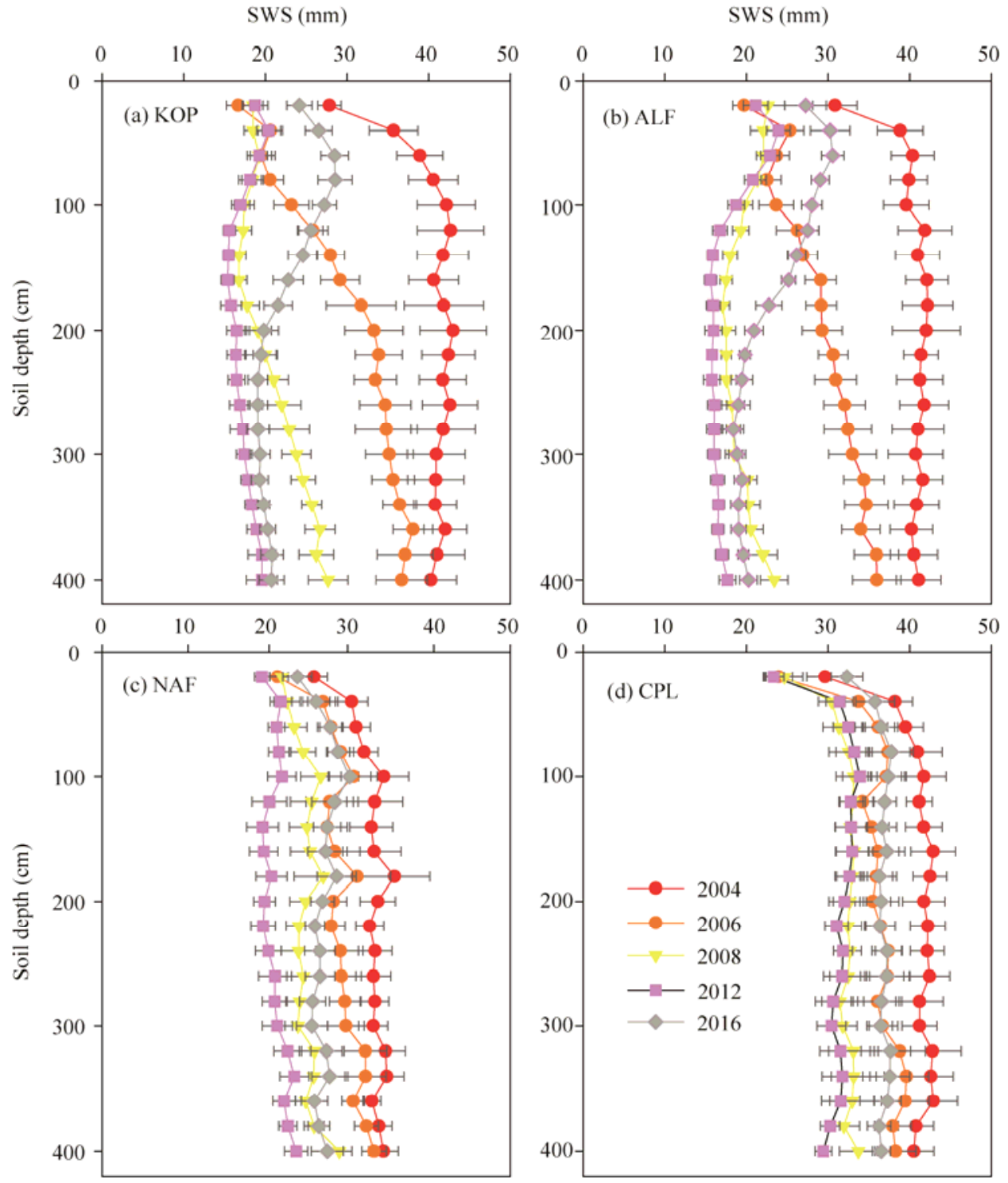

Fig. 4 Dynamics of soil water storage (SWS) in different soil depths under the four treatments during the period 2004-2016. KOP, korshinsk peashrub (shrubland); ALF, alfalfa (grassland); NAF, natural fallow (fallow land); CPL, millet (cropland). Bars represent standard deviations, $n=11$.

\section{Discussion}

\subsection{Land use and soil hydrological properties}

Knowledge on soil hydrological properties is critical for understanding soil water movement in the region (Zhang et al., 2006). Generally, values of soil BD, Ks, FC, and SOC for the surface soil layers were significantly variable among shrubland, grassland, and cropland (Wang et al., 2012; Zhang and Shangguan, 2016). In this study, shrubland soils had the lowest soil BD for the $0-10$ $\mathrm{cm}$ soil layer, probably due to the higher fine root biomass and porosity of that layer (Table 2; Fig. 2). It suggested that peashrubs have a positive effect on the hydrological properties of the surface soil layer (Wang et al., 2012). The BD of grassland soils was similar to that of cropland soils due in part to trampling during manual mowing of alfalfa and millet by local farmers. It has been noted in other studies that heavy pedestrian traffic negatively affects surface soil properties (Yüksek, 2009). For the $10-40 \mathrm{~cm}$ soil layer, there was no significant difference in BD 

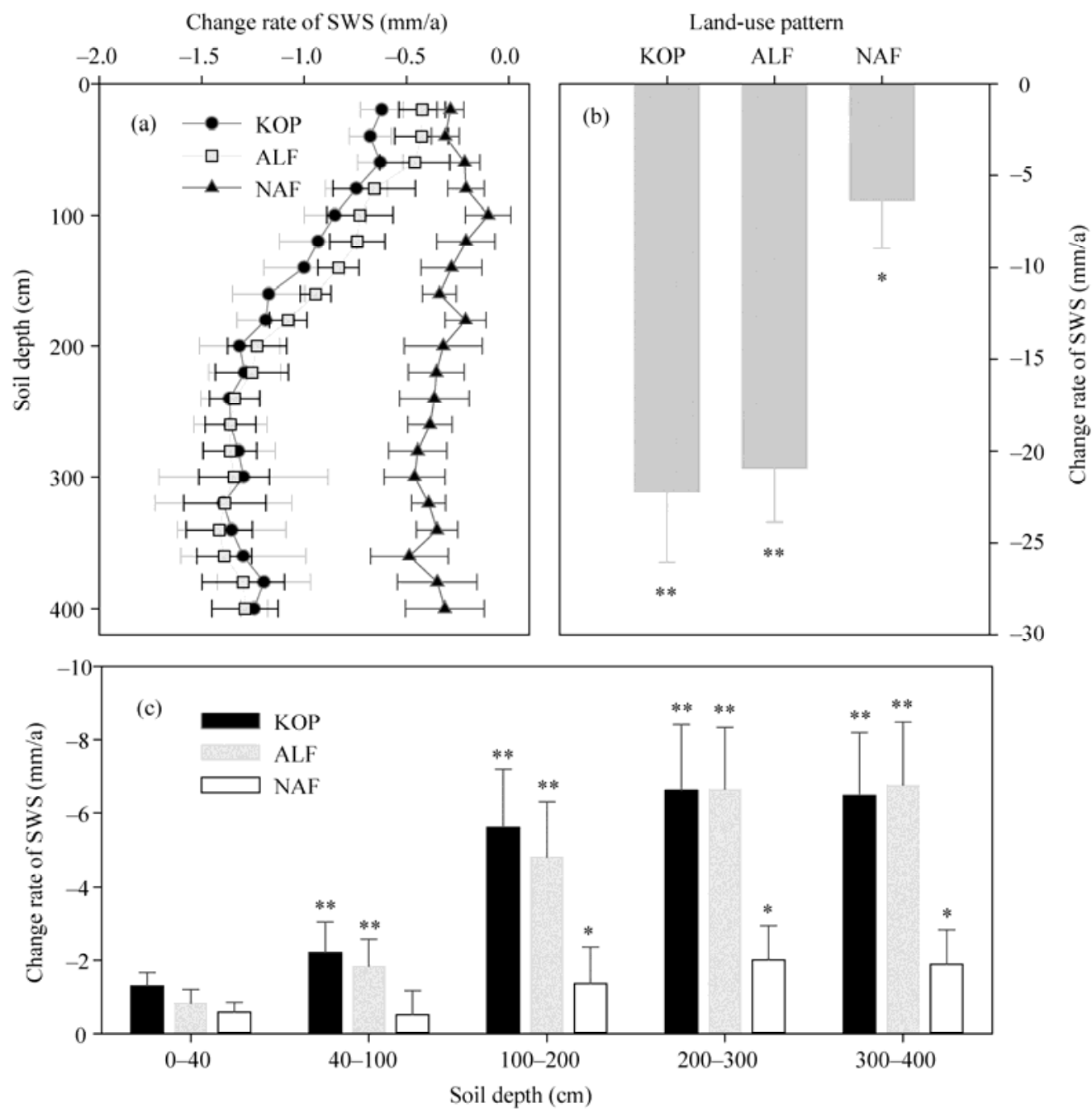

Fig. 5 Change rate of soil water storage (SWS) after vegetation restoration during 2004-2016 compared with control treatment (cropland). Negative values represent the decline in SWS after vegetation restoration; ${ }^{*}$ denotes significant correlation at $P<0.05$ level (1-tailed test); and ${ }^{* *}$ denotes significant correlation at $P<0.01$ level (2-tailed test). Bars represent standard deviations, $n=11$. KOP, korshinsk peashrub (shrubland); ALF, alfalfa (grassland); NAF, natural fallow (fallow land).

among shrubland, grassland, fallow land, and cropland soils, suggesting that peashrub and alfalfa had no clear effect on BD in deeper soil layers. This is consistent with the observations by Breuer et al. (2006) that BD was largely consistent in the 10-20 cm soil depth after conversion from grassland to cropland.

Generally, the mean Ks for all the sample soils was significantly higher than reported values $(0.05-0.58 \mathrm{~mm} / \mathrm{min})$ for the central and southern regions of the Loess Plateau. This could be due largely to the differences in soil parent materials in these regions (Li and Shao, 2006; Wang et al., 2008). In this study, the Ks values of shrubland and grassland soils were significantly $(P<0.05)$ higher than those of fallow land and cropland soils (Fig. 3b). This result suggests that revegetation by peashrub and alfalfa had more effect on hydraulic conductivity of surface soil layer (Wang et al., 2012). It was therefore concluded that revegetation by peashrub and alfalfa more deeply loosened the soil and thereby improved soil hydrological properties in the study area.

Soil FC is an indicator for several physical properties of soil, including soil texture, soil BD, soil porosity, and mechanical composition of soil (Scott, 2000). Therefore, knowledge on the temporal variability of soil FC is required to accurately capture soil hydrological processes during restoration. The increasing soil FC illustrated that soil water holding capacity in the $0-40 \mathrm{~cm}$ soil 
profile improved due to vegetation restoration. The main reason for the increase could be attributed to the high amounts of litter incorporated into the soil after revegetation with peashrub and alfalfa, increasing soil organic matter that in turn improved soil water retention (Wu et al., 2005).

SOC in the Loess Plateau was apparently smaller than the average value for China (Wu et al., 2003). Although all relatively small for the four land use types, vegetation restoration (with shrubland, grassland, and fallow land) still affected SOC distribution in the study area. Compared with the other three vegetation types, for example, shrubland significantly improved SOC concentration in the $0-40 \mathrm{~cm}$ soil layer after 13 years of revegetation (Fig. 3d). Fu et al. (2010) noted that shrubland is more effective than grassland in improving SOC under vegetation restoration. This could be explained in terms of higher aboveground biomass production (Fig. 2; Yimer et al., 2007), along with the incorporation of more organic matter into the soil after revegetation with peashrub, thus resulting in higher SOC (photosynthesis). Moreover, grassland and cropland were cut near the soil surface in this study, which could lead to smaller SOC input and output (respiration) in terms of litter fall, thus resulting in lower SOC (Fu et al., 2010). Compared with other vegetation types, cropland had the lowest SOC in the $0-10 \mathrm{~cm}$ soil layer (Fig. 3d). The minimum SOC in the $0-10 \mathrm{~cm}$ soil layer was likely due to the high runoff coefficient and erosion rate under cropland than under shrubland, grassland and fallow land (Zeng, 2006).

\subsection{Land use and profile SWS}

In situ soil moisture measurements in the northern Loess Plateau showed a significant decline in soil moisture under the four land use types (Figs. 1b and 4). This was partly consistent with observed volumetric water content under shrubland and cropland in the northern Loess Plateau region, China (Deng et al., 2016; Jia et al., 2017). The decline in SWS was mainly attributed to the decline in annual precipitation during 2004-2011 (Fig. 1a). During 2004-2016, mean annual precipitation for 2005-2006 (303 mm) and for 2009-2011 (382 mm) was consistently lower than that for 2004-2016 (449 mm).

Induced by vegetation restoration, improved soil structure meant more water in the $0-40 \mathrm{~cm}$ surface soil layer (Wu et al., 2016). In this study, however, the relationship between SWS and soil hydrological properties (BD, Ks, FC, and SOC) considerably varied for the $0-40 \mathrm{~cm}$ soil layer (Table 3). Furthermore, there was no significant change in SWS in the $0-40 \mathrm{~cm}$ soil layer during revegetation (Fig. 5). This was mainly explained by the difference in mean annual precipitation during 2004-2016 (Fig. 1a), combined with the effect of transpiration and soil evaporation (Seneviratne et al., 2010; Zhang and Shangguan, 2016). Jin et al. (2011) also noted that annual precipitation was an important factor for SWC in the 0-200 cm soil layer in the semi-arid Loess Plateau region, China. In addition, Wang et al. (2011) found that the evolution of soil water content is a complex process and that other factors such as soil properties and land use are also important factors for the surface soil layer.

SWS significantly decreased under korshinsk peashrub and alfalfa in deep soil layers during the study period (Fig. 5), which is consistent with the results of Jia et al. (2017). However, the decline rate of SWS under fallow land was much lower than those under korshinsk peashrub and alfalfa. In deep soil layers, SWS is primarily influenced by root water uptake (Zeng et al., 2011). Generally, SWS in the deep soil layers was lower under deep-rooted crops (e.g., peashrub and alfalfa) than under shallow-rooted crops (e.g., fallow land and cropland) (Zeng et al., 2011; Fang et al., 2016). Thus, soil water use by peashrub and alfalfa cause desiccation of the deep soil layers (below $40 \mathrm{~cm}$ ) after 8 years of growth, indicating that plant age influenced SWC (Yan et al., 2015). It was concluded that revegetation with peashrub and alfalfa decreased soil water in deep soil layers in the Loess Plateau region, China. In addition, the decrease in SWS under natural restoration cannot be considered as degradation, especially in terms of SWS under shrubland and grassland (Fig. 5c; Jia and Shao, 2014). Therefore, it was considered that natural restoration did reduce soil water as much revegetation with peashrub and alfalfa. Natural restoration increased soil hydrological properties, such as FC and SOC (Fig. 3). Thus far, it can only be assumed that natural fallow was better than revegetation with peashrub and alfalfa in terms of soil hydrological processes in the semi-arid Loess Plateau region, China. Thus, optimized vegetation restoration 
with low water use or natural regrowth was needed for a balanced soil water use and sound hydrological properties for the vegetation restoration program in the Loess Plateau region, China (Cao et al., 2011).

Table 3 Pearson's correlation coefficients between soil water storage and soil properties for all sample soils in the $0-40 \mathrm{~cm}$ soil layer

\begin{tabular}{|c|c|c|c|c|c|c|}
\hline $\begin{array}{l}\text { Soil depth } \\
\quad(\mathrm{cm})\end{array}$ & & SWS & $\mathrm{BD}$ & Ks & $\mathrm{FC}$ & SOC \\
\hline \multirow{5}{*}{$0-10$} & SWS & 1.000 & & & & \\
\hline & $\mathrm{BD}$ & $-0.370^{*}$ & 1.000 & & & \\
\hline & Ks & 0.323 & $-0.816^{* *}$ & 1.000 & & \\
\hline & $\mathrm{FC}$ & $0.372^{*}$ & 0.316 & 0.315 & 1.000 & \\
\hline & SOC & 0.200 & -0.128 & 0.131 & 0.285 & 1.000 \\
\hline \multirow{5}{*}{ 10-20 } & sws & 1.000 & & & & \\
\hline & $\mathrm{BD}$ & -0.131 & 1.000 & & & \\
\hline & Ks & 0.325 & $-0.699^{* *}$ & 1.000 & & \\
\hline & $\mathrm{FC}$ & $0.339^{*}$ & -0.111 & 0.037 & 1.000 & \\
\hline & SOC & 0.085 & $-0.447^{* *}$ & $0.418^{*}$ & $0.462^{* *}$ & 1.000 \\
\hline \multirow{5}{*}{$20-40$} & sws & 1.000 & & & & \\
\hline & $\mathrm{BD}$ & $-0.385^{*}$ & 1.000 & & & \\
\hline & Ks & $0.385^{*}$ & $-0.999^{* *}$ & 1.000 & & \\
\hline & $\mathrm{FC}$ & $0.496^{* *}$ & -0.261 & 0.261 & 1.000 & \\
\hline & SOC & $0.482^{* *}$ & $-0.650^{* *}$ & $0.650^{* *}$ & 0.238 & 1.000 \\
\hline
\end{tabular}

Note: SWS, soil water storage; BD, soil bulk density; Ks, saturated hydraulic conductivity; FC, field capacity; SOC, soil organic carbon; ${ }^{*}$ denotes significant correlation at $P<0.05$ level (1-tailed test); ${ }^{* *}$ denotes significant correlation at $P<0.01$ level ( 2 -tailed test).

\section{Conclusions}

The effects of converting cropland (millet or potato) into grassland (alfalfa and fallow land) and shrubland (peashrub) on soil hydrological properties (including soil water storage) were analyzed for the semi-arid Loess Plateau region, China. The results showed that after 13 years of grassland and shurbland restoration, soil bulk density for the $0-40 \mathrm{~cm}$ soil layer significantly decreased, while saturated hydraulic conductivity, field capacity, and soil organic carbon significantly increased. Compared with cropland and fallow land, soil water storage in the $0-400 \mathrm{~cm}$ soil profile considerably declined in restored ecosystems with alfalfa and peashrub. It was therefore concluded that revegetation with alfalfa and peashrub improved soil hydrological properties, but increased soil drying in the northern Loess Plateau region, China. Future vegetation restoration strategies should consider using local species that use less water or leaving land uncultivated for natural regrowth. Either way, it will improve soil properties without causing severe soil water crisis in the Loess Plateau region of China. The findings of this study could be useful for ecological studies and policy making on similar water-scarce regions in the world.

\section{Acknowledgements}

This research was supported by the National Natural Science Foundation of China (41501233, 41601216, 41390461), the National Key Project for Research and Development (2016YFC0501605), the Youth Innovation Promotion Association of the Chinese Academy of Sciences (2017076) and the Open Research Fund of the State Key Laboratory of Soil Erosion and Dryland Farming on the Loess Plateau (A314021402-1806). The authors are indebted to the editors and reviewers for the constructive comments and suggestions on the article.

\section{References}

Cao S X, Chen L, Yu X X. 2009. Impact of China's Grain for Green Project on the landscape of vulnerable arid and semi-arid agricultural regions: a case study in northern Shaanxi Province. Journal of Applied Ecology, 46(3): 536-543. 
Cao S X, Chen L, Shankman D, et al. 2011. Excessive reliance on afforestation in China's arid and semi-arid regions: Lessons in ecological restoration. Earth-Science Reviews, 104(4): 240-245.

Chen H S, Shao M A, Li Y Y. 2008. Soil desiccation in the Loess Plateau of China. Geoderma, 143(1-2): 91-100.

Deng L, Liu G B, Shangguan Z P. 2014. Land-use conversion and changing soil carbon stocks in China's 'Grain-for-Green' Program: a synthesis. Global Change Biology, 20(11): 3544-3556.

Deng L, Yan W M, Zhang Y W, et al. 2016. Severe depletion of soil moisture following land-use changes for ecological restoration: evidence from northern China. Forest Ecology and Management, 366: 1-10.

Deng L, Liu S G, Kim D G, et al. 2017. Past and future carbon sequestration benefits of China's grain for green program. Global Environmental Change, 47: 13-20.

Fang X N, Zhao W W, Wang L X, et al. 2016. Variations of deep soil moisture under different vegetation types and influencing factors in a watershed of the Loess Plateau, China. Hydrology and Earth System Sciences, 20(8): 3309-3323.

Fu W, Huang M B, Gallichand J, et al. 2012. Optimization of plant coverage in relation to water balance in the Loess Plateau of China. Geoderma, 173-174: 134-144.

Fu X L, Shao M A, Wei X R, et al. 2010. Soil organic carbon and total nitrogen as affected by vegetation types in Northern Loess Plateau of China. Geoderma, 155(1-2): 31-35.

Gee G W, Or D. 2002. Particle-size analysis. In: Dane J H, Topp G C. Methods of Soil Analysis. Part 4. Physical Methods. Madison: Soil Science Society of America, 255-289.

Issa O M, Valentin C, Rajot J L, et al. 2011. Runoff generation fostered by physical and biological crusts in semi-arid sandy soils. Geoderma, 167-168: 22-29.

Jia X X, Shao M A, Zhang C C, et al. 2015. Regional temporal persistence of dried soil layer along South-North transect of the Loess Plateau, China. Journal of Hydrology, 528: 152-160.

Jia X X, Shao M A, Zhu Y J, et al. 2017. Soil moisture decline due to afforestation across the Loess Plateau, China. Journal of Hydrology, 546: 113-122.

Jia Y H, Shao M A. 2014. Dynamics of deep soil moisture in response to vegetational restoration on the Loess Plateau of China. Journal of Hydrology, 519: 523-531.

Jin T T, Fu B J, Liu G H, et al. 2011. Hydrologic feasibility of artificial forestation in the semi-arid Loess Plateau of China. Hydrology and Earth System Sciences, 15(8): 2519-2530.

Kanwar R S, Rizvi H A, Ahmed M, et al. 1989. Measurement of field-saturated hydraulic conductivity by using Guelph and Velocity permeameters. Transactions of the ASAE, 32(6): 1885-1890.

Li Y Y, Shao M A. 2006. Change of soil physical properties under long-term natural vegetation restoration in the Loess Plateau of China. Journal of Arid Environments, 64(1): 77-96.

Liu B X, Shao M A. 2016. Response of soil water dynamics to precipitation years under different vegetation types on the northern Loess Plateau, China. Journal of Arid Land, 8(1): 47-59.

Liu Y L, Pan Z H, Zhuang Q L, et al. 2015. Agriculture intensifies soil moisture decline in Northern China. Scientific Reports, 5: 11261.

Malagnoux M. 2007. Arid Land Forests of the World: Global Environmental Perspectives. Rome, Italy: Food and Agriculture Organization of the United Nations (FAO).

Nelson D W, Sommers L E. 1982. Total carbon, organic carbon, and organic matter. In: Page A L, Miller R H, Keeney D R. Methods of Soil Analysis, Part 2. Chemical and Microbial Properties (2 ${ }^{\text {nd }}$ ed.). Madison: Agronomy Society of America, 539-552.

Scott H D. 2000. Soil Physics: Agricultural and Environmental Applications. Iowa: Iowa State University Press, 350-352.

Seneviratne S I, Corti T, Davin E L, et al. 2010. Investigating soil moisture-climate interactions in a changing climate: a review. Earth-Science Reviews, 99(3-4): 125-161.

Shi H, Shao M A. 2000. Soil and water loss from the Loess Plateau in China. Journal of Arid Environments, 45(1): 9-20.

Wang A H, Lettenmaier D P, Sheffield J. 2011. Soil moisture drought in China, 1950-2006. Journal of Climate, 24(13): $3257-3271$.

Wang L, Wang Q J, Wei S P, et al. 2008. Soil desiccation for Loess soils on natural and regrown areas. Forest Ecology and Management, 255(7): 2467-2477.

Wang L, Mu Y, Zhang Q F, et al. 2012. Effects of vegetation restoration on soil physical properties in the wind-water erosion region of the Northern Loess Plateau of China. Clean-Soil Air Water, 40(1): 7-15.

Wang Y Q, Shao M A, Liu Z P, et al. 2012. Regional spatial pattern of deep soil water content and its influencing factors. Hydrological Sciences Journal, 57(2): 265-281. 
Wu G L, Liu Y, Fang N F, et al. 2016. Soil physical properties response to grassland conversion from cropland on the semi-arid area. Ecohydrology, 9(8): 1471-1479.

Wu H B, Guo Z T, Peng C H. 2003. Land use induced changes of organic carbon storage in soils of China. Global Change Biology, 9(3): 305-315.

Wu H S, Chen X M, Ye M B, et al. 2005. Moisture characteristics and their effect factors of main paddy soils in Tai lake region. Journal of Soil and Water Conservation, 19(1): 181-183, 187. (in Chinese)

Yan W M, Deng L, Zhong Y Q W. 2015. The characters of dry soil layer on the Loess Plateau in China and their influencing factors. PLoS ONE, 10(8): e0134902.

Yang L, Wei W, Chen L, et al. 2012. Spatial variations of shallow and deep soil moisture in the semi-arid Loess Plateau, China. Hydrology and Earth System Sciences, 16(9): 3199-3217.

Yang L, Wei W, Chen L D, et al. 2014. Response of temporal variation of soil moisture to vegetation restoration in semi-arid Loess Plateau, China. CATENA, 115: 123-133.

Yimer F, Ledin S, Abdelkadir A. 2007. Changes in soil organic carbon and total nitrogen contents in three adjacent land use types in the Bale Mountains, south-eastern highlands of Ethiopia. Forest Ecology and Management, 242(2-3): 337-342.

Yüksek T. 2009. Effect of visitor activities on surface soil environmental conditions and aboveground herbaceous biomass in Ayder Natural Park. Clean-Soil Air Water, 37(2): 170-175.

Zeng C. 2006. Study on the soil water cycle on slope with different conditions of vegetation covering in water-wind erosion crisscross region. MSc Thesis. Yangling: Northwest A\&F University. (in Chinese)

Zeng C, Shao M A, Wang Q J, et al. 2011. Effects of land use on temporal-spatial variability of soil water and soil-water conservation. Acta Agriculturae Scandinavica, Section B-Soil \& Plant Science, 61(1): 1-13.

Zhang S L, Lövdahl L, Grip H, et al. 2007. Soil hydraulic properties of two loess soils in China measured by various field-scale and laboratory methods. CATENA, 69(3): 264-273.

Zhang Y W, Shangguan Z P. 2016. The change of soil water storage in three land use types after 10 years on the Loess Plateau. CATENA, 147: 87-95.

Zhang Z H, Li X Y, Jiang Z Y, et al. 2013. Changes in some soil properties induced by re-conversion of cropland into grassland in the semiarid steppe zone of Inner Mongolia, China. Plant and Soil, 373(1-2): 89-106. 